\title{
POPULAR ATTITUDES TOWARDS TREES IN AN URBAN CONTEXT USING THE AHP
}

\author{
Farideh Delavari-Edalat and M. Reza Abdi \\ Bradford University School of Management \\ Emm Lane, Brdford, BD9 4JL. U.K. \\ r.abdi@ bradford.ac.uk
}

Key words: AHP, biophilia, environment management

Summary: Biophilia is the idea that insists on the dependency of human identity on the relationship with nature. The idea has been developed in recent years and consists of nine tendencies. Aim of this research is to identify the significant popular attitudes towards trees in an urban area based on biophilia tendencies. This research employs the Analytical Hierarchical Process (AHP) to consider basic human instincts and human preferences about their surrounding areas along with environmental factors. Accordingly, the model facilitates the analysis of the results with respect to biophilia tendencies as criteria. Consequently a link between human feeling about urban trees and environmental factors can be found in monitoring the performance analysis.

\section{Introduction}

People are visiting parks every day, walking, sitting and watching nature and specially the trees. They want to be inspired, refreshed, comforted, and reassured by their surroundings. They want spaces that will make them more dynamic and healthy, and especially spaces in which they love to be. The appeal of these feelings may lie in its multiple connections to the natural environment and, consequently, biophilia. If we find ourselves relaxing and feeling a pleasant surge of energy welling up inside after watching the bright, beautiful colours of autumn trees and smelling the fresh air in the woods, then we are experiencing "Biophilia," an emerging area of scientific research.

A growing number of studies show that features of environments have consequences for psychological, physical and social well being. Beneficial contact with nature can be sustained in a variety of ways and the work in this area could provide the beginning of evidence for a potential link between nature and people. The idea that human affinity with nature is inherent in the way our nervous systems develop called biophilia. The biophilia hypothesis boldly asserts the existence of a biologically based, inherent human need to affiliate with life and lifelike processes (Wilson 1984). Kellert (1996a) has refined a typology of nine values, which he suggests reflect a range of physical, emotional, and intellectual expressions of the biophilic tendency to associate with nature. These hypothesized expressions of the biophilia tendencies are referred to as the utilitarian, naturalistic, ecologistic-scientific, aesthetic, symbolic, humanistic, moralistic, dominionistic, and negativistic valuations of nature.

The use of the utilitarian term is restricted to the conventional notion of material value: the physical benefits derived from nature as a fundamental basis for human sustenance, protection, and security. The naturalistic tendency can be regarded as the satisfaction derived from direct contact with nature. The naturalistic value encompasses a sense of fascination, wonder, and awe derived from a close experience of nature's diversity and complexity. Ecological insight has probably conferred distinctive advantages in the meeting and mastering of life's physical and mental requirements-including increased knowledge, the honing of observational and recording skills, and the recognition of potential material uses of nature through direct exploitation. The scientific experience of nature, in contrast to the ecologistic, involves a greater emphasis on the physical and mechanical functioning of biophysical entities as well as a related stress on issues of morphology, taxonomy, and physiological process. The physical beauty of nature is certainly among its most powerful appeals to the human. Beauty of nature exerts a powerful aesthetic 
impact on most people, often accompanied by feelings of awe at the extraordinary physical appeal and beauty of the natural world. The use of nature as symbol is perhaps most critically reflected in the development of human language and the complexity and communication of ideas fostered by this symbolic methodology. The humanistic experience of nature reflects feelings of deep emotional attachment to individual elements of the natural environment which can even be expressed as a feeling of love for nature. The moralistic experience of nature encompasses strong feelings of affinity, ethical responsibility, and even reverence for the natural world. The dominionistic experience of nature reflects the desire to master the natural world. And the negativistic experience of nature is characterized by sentiments of fear, aversion, and antipathy toward various aspects of the natural world.

The study is concerned with methods and techniques that support the values of the biophilia hypothesis as the research framework. The research intends to explore perceptions of trees in an urban context. The research investigates popular attitudes towards trees in Liverpool's woodland areas in relation to the biophilia hypothesis. To achieve the stated objectives a quantitative methodology is designed which is followed by a proposed hierarchical model to analyse the information of the questionnaires. Accordingly, the output of the questionnaires will be considered as an input for the proposed model in order to analyse the criteria.

\section{Methodology}

This study was concern with geography, biology and environmental psychology as follows:

a. geography: parks and out-doors environment in an urban area,

b. biology: biophilia theories which concern the genetic basis of the human relationship to nature,

c. environmental psychology including work that has examined the psychological manifestations of people's relationship with nature with a focus on trees.

The survey has been undertaken to gather people's views towards trees across the city of Liverpool. It was decided that the relevant population from which to draw the sample from were the general public, who use parks and out door environments in the city. Within the interviews there were 52 respondents, who were a mix of population in terms of age, gender, ethnics, and so on.

The data collection tool used was a quantitative interview accompanied by a questionnaire which was designed to discover the valuation of our objectives which is: popular attitude/mood toward trees in urban areas in relation to biophilia values. The questionnaire criteria were defined based on the biophilia hypothesis, which are: utilitarian, naturalistic, ecologistic-scientific, aesthetic, symbolic, humanistic, moralistic, dominionistic, and negativistic. Each question could be answered by one of five scales, which show values as follows: $1=$ completely disagree, $2=$ disagree, $3=$ neither agree no disagree, $4=$ agree, $5=$ completely agree. Some information was indicated by the interviewer, such as weather (sunny or cloudy), gender (male or female), and month of the year.

\section{The AHP model}

This research employs the AHP as a multi-criteria justification approach for strategic environmental management in urban areas. In this respect, the hierarchy consists of general levels i.e. goal, criteria, and sub-criteria. As shown in Figure (1) the parameters for this model can be hierarchically categorised into three levels as follows:

Level 1: goal: popular attitude towards trees

Level 2: criteria: utilitarian, naturalistic, ecologistic-scientific, aesthetic, symbolic, humanistic, moralistic, dominionistic, and negativistic which are defined based on the biophilia hypothesis.

Level 3: sub-criteria: gender (male, female), weather (sunny, cloudy), and month of the year (July, August, December). 


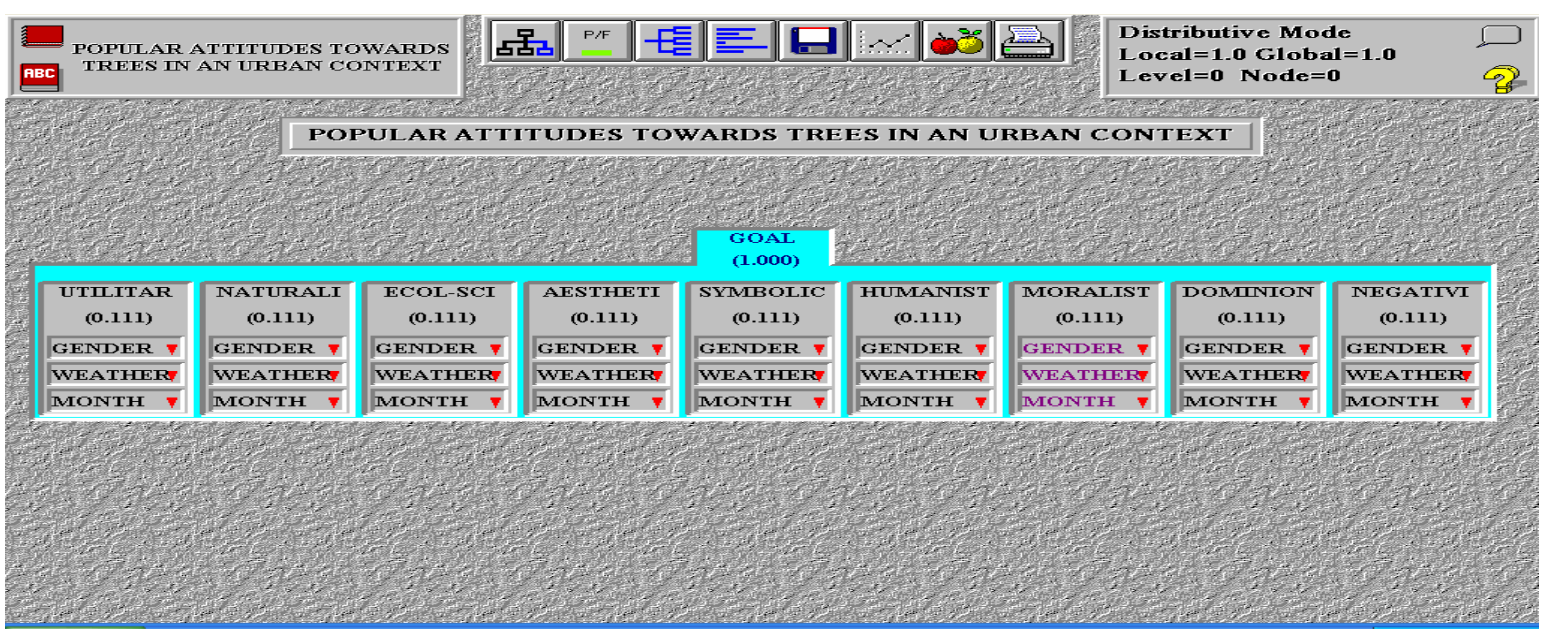

Figure (1) the structure of the AHP model built in Expert Choice

\section{Results and Analysis}

The analysis of the AHP results could be a base for environmental managers to consider people's opinions and their feelings for environmental planning and decision making for urban woodland areas development. The proposed model is generic and intended to consist of managerial parameters. The strategy of how sensitive the sub-criteria are with respect to criteria and goal can be interpreted through the parametric analysis of the model. As shown in Figure (2), the criteria (utilitarian, naturalistic, ecologistic-scientific, aesthetic, symbolic, humanistic, moralistic, dominionistic, and negativistic).

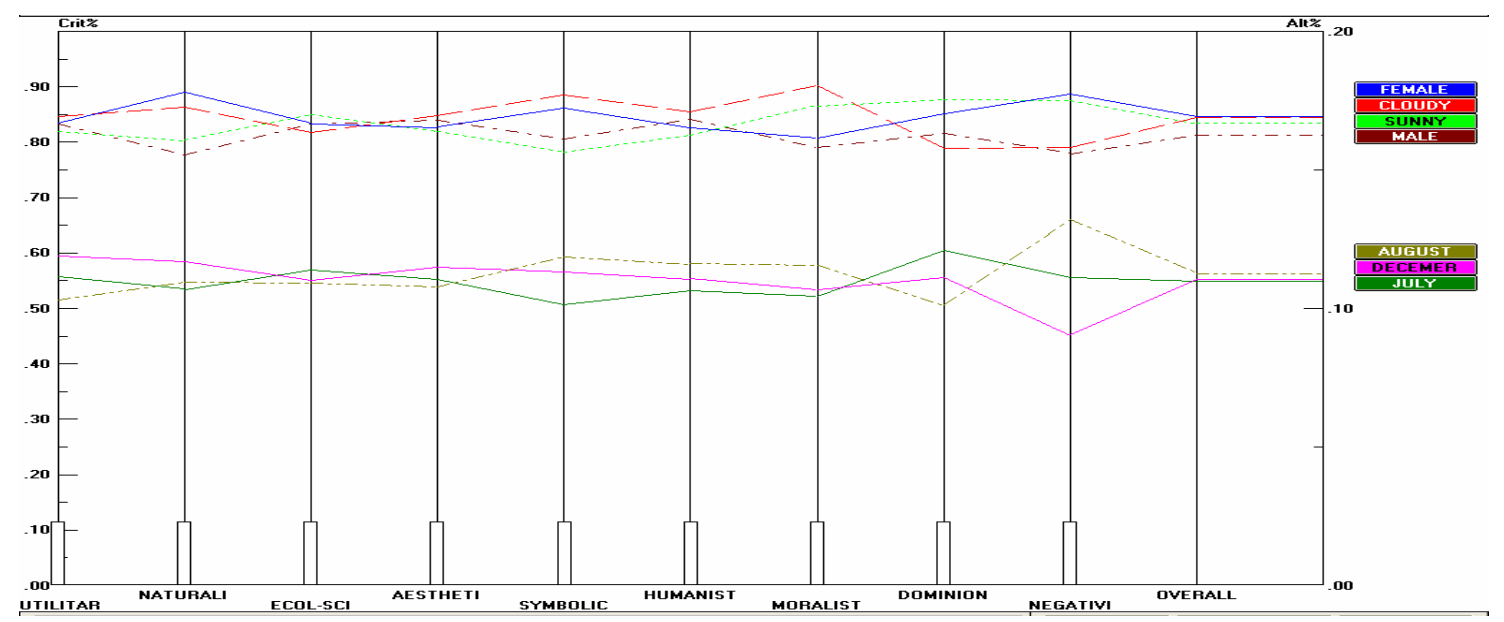

Figure (2) performance sensitivity graph with respect to criteria and goal

Once the model is built, the next step for achieving a numerical result is to evaluate the elements by entering data which are the results from the previous chapter data collected by questionnaire intended in order to prioritise goal, criteria and sub-criteria. Running the model, the assessment process creates a synthesis judgement that combines all the separate judgments and priorities leading to the defined alternatives. As shown in Figure (3) the sub-criteria for biophilia values is sorted in the sequence female = 
cloudy $>$ sunny $>$ male $>$ August $>$ December $=$ July with the priorities 0.169, 0.169, 0.167, 0.163, 0.113, 0.110 , and 0.110 respectively. This means that females and cloudy weather have more influence on the goal than any others.

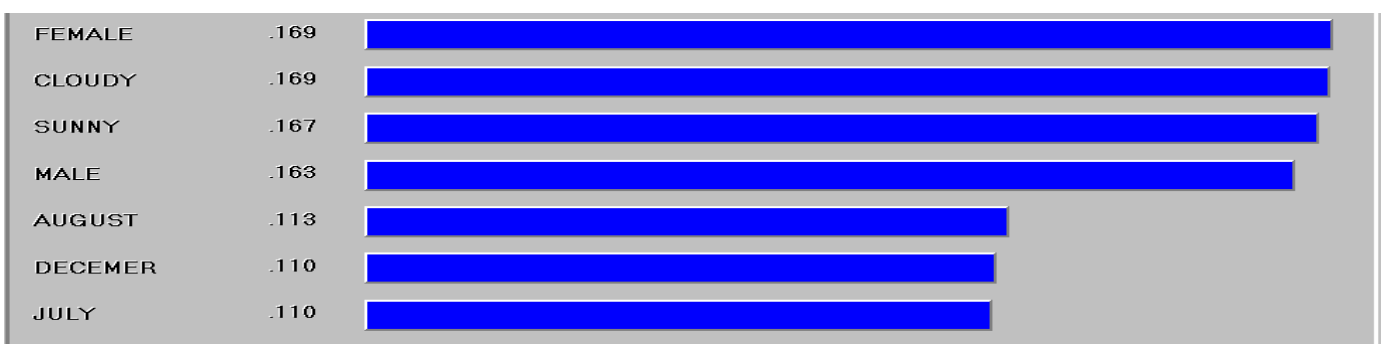

Figure (3) sub-criteria with respect to goal

Due to the existence of the nine criteria in the model, some important issues relevant to the results are discussed as follows.

\subsection{Sub-criteria analysis with respect to the naturalistic criterion}

As shown in Figure (4), female is the most appropriate sub-criterion with respect to the naturalistic criterion. The analysis shows there is significant difference between males and females and this indicates that females have more satisfaction from direct experience with nature. And also people in cloudy weather are more naturalistic than in sunny weather.

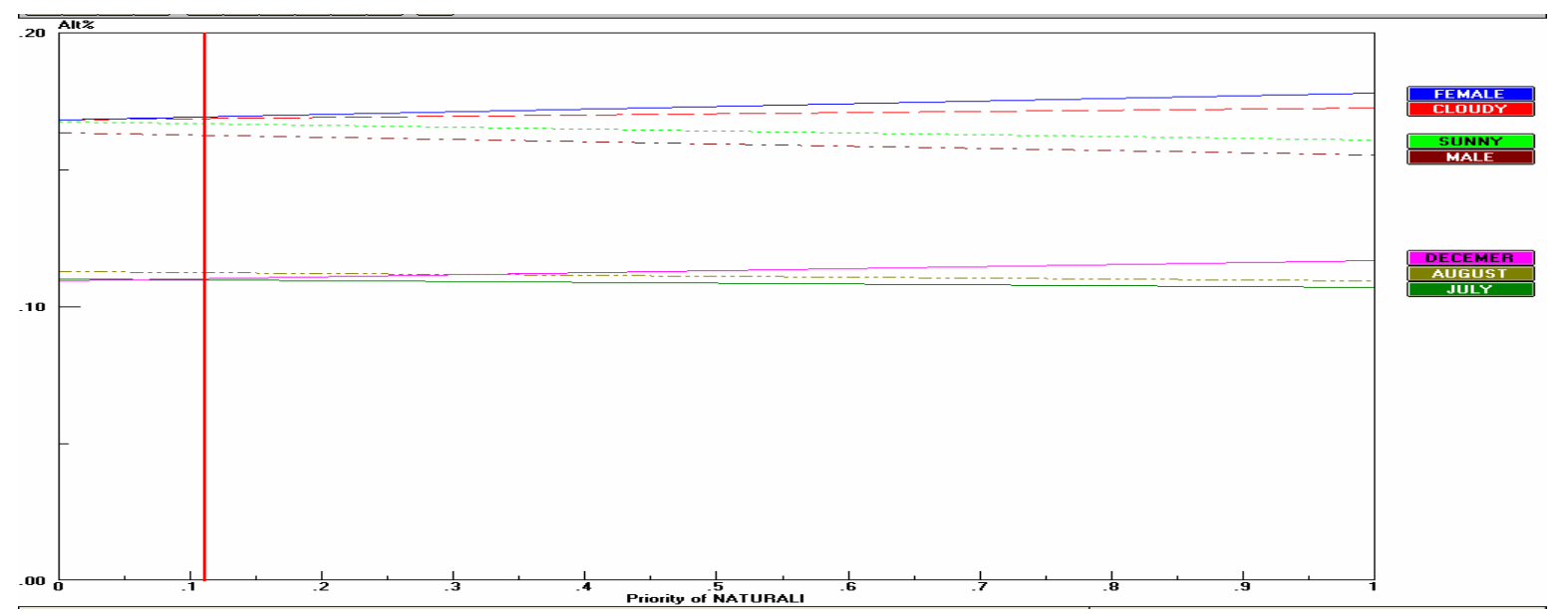

Figure (4) sensitivity graph with respect to the naturalistic criterion

4.2 Sub-criteria analysis with respect to the symbolic criterion

As shown in Figure (5), cloudy weather is the most appropriate sub-criterion with respect to the symbolic criterion. The analysis shows that there is a significant difference between sunny weather and cloudy weather. This explores the fact that in cloudy weather people see trees more metaphorically than in sunny weather. And also females have more symbolic feelings than males about urban woodlands. 


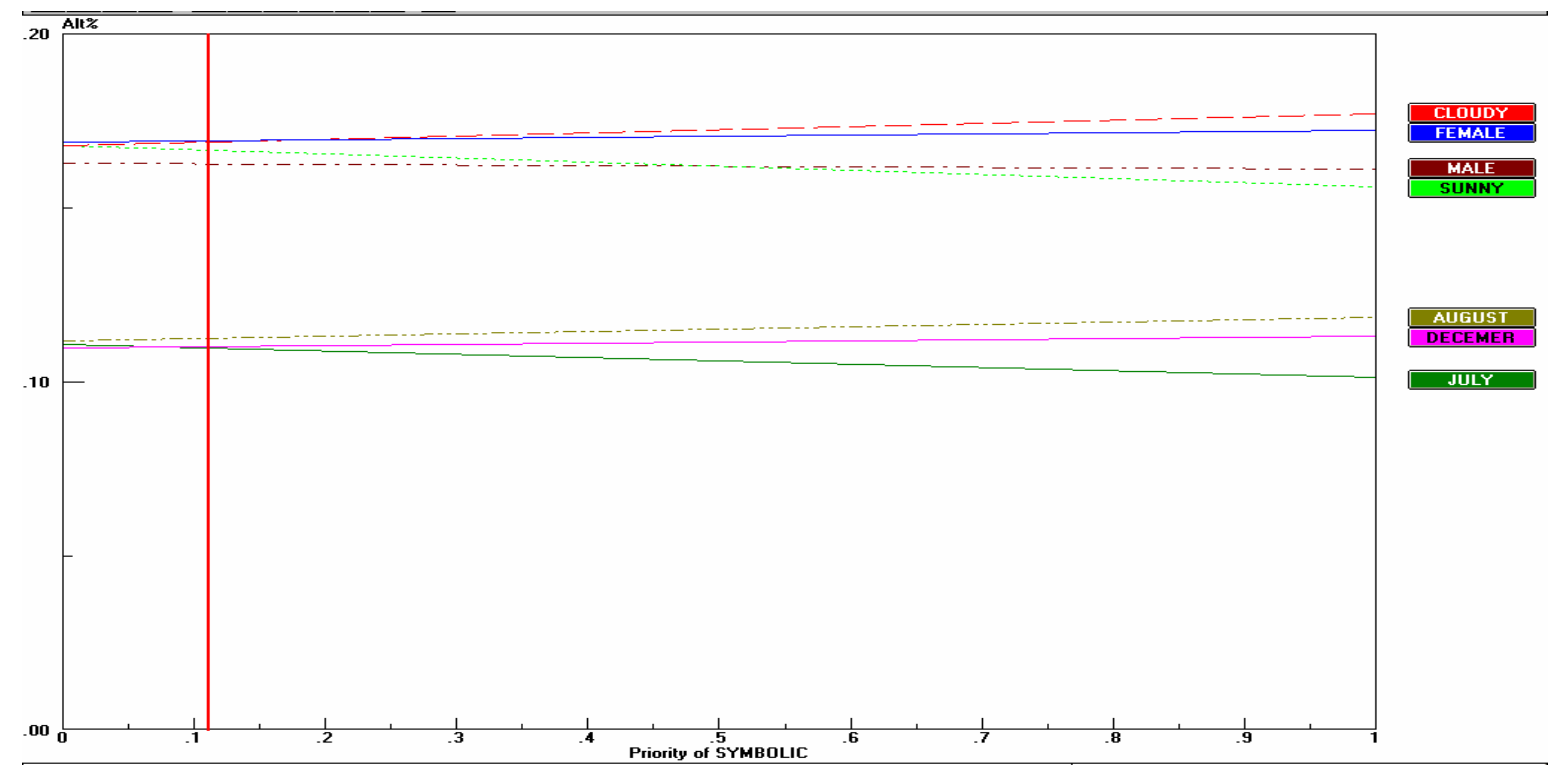

Figure (5) sensitivity graph with respect to the symbolic criterion

\subsection{Sub-criteria analysis with respect to the dominionistic criterion}

As shown in Figure (6), sunny weather is the most appropriate sub-criterion with respect to the dominionistic criterion. The analysis shows there is significant difference between sunny and cloudy weather which shows people in sunny weather have stronger feelings about mastery, and dominance of trees. And also analysis indicates females have more feelings about dominance of trees than males.

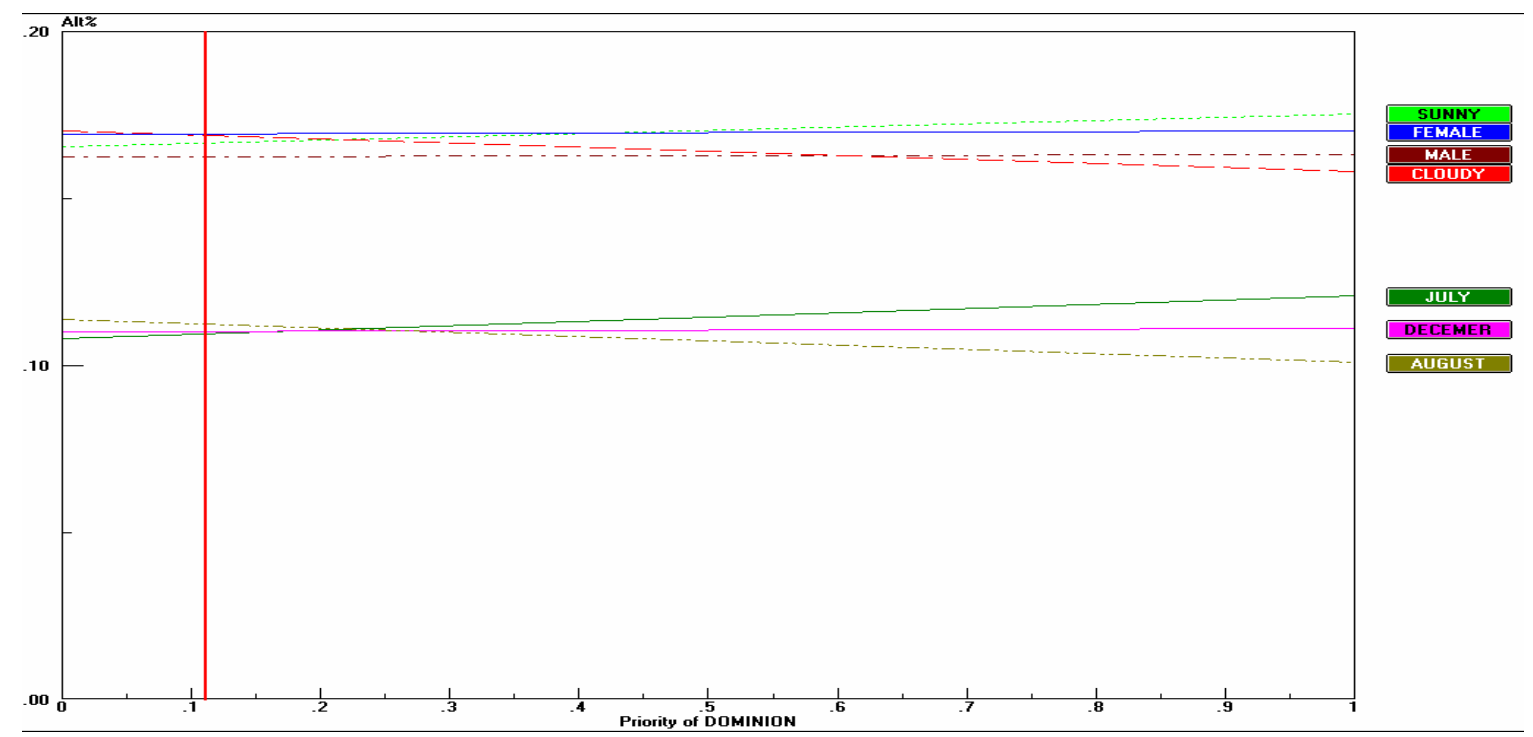

Figure (6) sensitivity graph with respect to the dominionistic criterion 


\subsection{Sub-criteria analysis with respect to the negativistic criterion}

As shown in Figure (7), female is the most appropriate sub-criterion with respect to the negativistic criterion. The analysis shows that there is a significant difference between females and males, sunny and cloudy weather and also between August and December with respect to the negativistic criterion. This specifies that females have more negative feelings about urban woodlands than males. Also in sunny weather people have more negative feelings about urban woodlands than in cloudy weather.

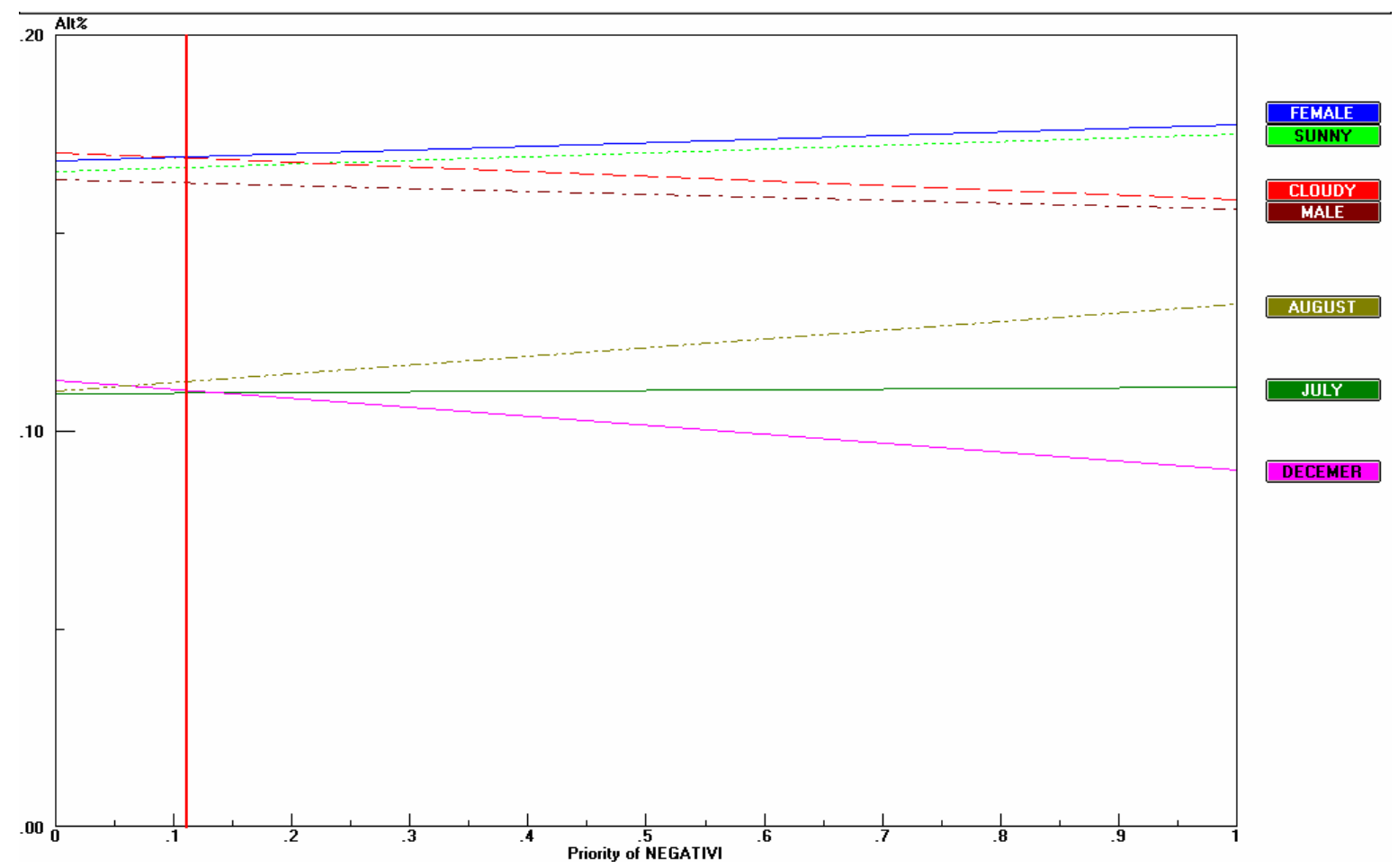

Figure (7) sensitivity graph with respect to the negativistic criterion

\section{Conclusion}

The biophilia hypothesis a framework for this research to understand how people relate to nature especially trees. Analysis of the results presented the identification of value types that have been found to represent popular attitudes towards trees in Liverpool woodland areas. The importance of understanding what is important to people in relation to trees based on biophilia values was investigated and highlighted in the urban areas. The investigation was based on a quantitative interview which was applied to the general population in Liverpool parks.

The AHP model was used to analyse the data findings in this research. Having analysed the results of the AHP model, overall results for the goal show being female and cloudy weather are the most affective parameters on the goal (popular attitudes towards trees based on the biophilia hypothesis in urban areas). In addition, the results show people think more symbolically about trees in cloudy weather and also that females have more symbolic feeling about trees than males. On the other hand, people have stronger feelings about mastery, and dominance of urban woodlands in sunny weather. 


\section{References}

Expert Choice. (1999) Expert Choice Software. Expert Choice Inc., Pittsburgh, PA.

Kellert, S.R. (1996) The Value of Life. Biological Diversity and Human Society, Island Press.

Kellert, S. R. and Wilson, E. O. (1993) The Biophilia Hypothesis. Washington, D.C.: Island Press (ISBN: 1-55963-147-3).

Saaty, T.L. (1996) Decision making with dependence and feedback. The Analytic Network Process, RWS Publications, Pittsburgh, U.S.

Saaty, T.L., and Vergas, L.G. (1990)_Multicriteria decision making Anlytical Hierarchical Process._RWS Publications, Pittsburgh, U.S.

Saaty, T.L. (1980) The Analytical Hierarchical Process, McGraw Hill, New York.

Wilson, E.O. (1984) Biophilia The Human Bond with Other Species. Harvard University Press. 